\title{
EEG Sleep and the Cholinergic REM Induction Test in Anorexic and Bulimic Patients
}

\author{
Christoph Lauer, Jürgen Zulley, Jürgen-Christian Krieg, Dieter Riemann, \\ and Mathias Berger
}

Received April 6, 1987; revised version received November 19, 1987; accepted December 4, 1987.

\begin{abstract}
The electroencephalographic (EEG) sleep of 20 anorexic patients, 10 bulimic patients, and 10 age-matched healthy controls was studied. In addition, six anorexic patients and six bulimic patients had a cholinergic rapid eye movement (REM) sleep induction test (RIT) performed with the cholinergic agent RS 86 . The three samples showed no major differences in sleep patterns. The same held true when attention was focused on patients who additionally met $D S M-I I I$ criteria for major depression. The RIT results were similar in the patients with eating disorders and in controls, but differed from those reported in depressives. Therefore, the present study found no hints of depression-like sleep patterns in patients with eating disorders.
\end{abstract}

Key Words. Anorexia nervosa, bulimia, electroencephalographic sleep, REM sleep induction test, depression.

The last decade has witnessed increased research interest in eating disorders such as anorexia nervosa and bulimia. The most prominent lines of inquiry were clinical reports, family history, treatment studies, and followup investigations. Some of this research indicated that eating disorders and affective disorders may be related psychiatric disturbances (for overview of literature, see Halmi, 1985; Levy and Dixon, 1985; Swift et al., 1986). Such a relationship would have important theoretical and clinical implications. To date, however, there is still an ongoing discussion as to whether the mood disturbance is secondary to the eating disorder (e.g., Bruch, 1973; Fairburn, 1983) or whether anorexia nervosa and bulimia both are variants of an affective disorder (e.g., Cantwell et al., 1977; Hudson et al., 1983).

In sleep research, relatively little attention has been paid to the question of similarities between the sleep patterns of patients with eating disorders and those with affective disorders. This is surprising because abnormalities of rapid eye movement (REM) sleep (i.e., shortened REM latency and increased REM density) are generally accepted as characteristic biological abnormalities of primary depression (e.g., Gillin et al., 1984; Kupfer, 1986).

Christoph Lauer, Ph.D., and Jürgen Zulley, Ph.D., are Psychologists; Jürgen-Christian Krieg, M.D., is Psychiatrist and Neurologist; Dieter Riemann is Psychologist; and Mathias Berger, M.D., is Professor of Psychiatry, Max-Planck-Institute for Psychiatry. Munich. FRG. M. Berger and D. Riemann are now at the Central Institute of Mental Health, Mannheim, FRG. (Reprint requests to Dr. Ch. Lauer at his current address: Department of Psychiatry, University of Freiburg, Hauptstr. 5, 7800 Freiburg, FRG.) 
The first polysomnographic study in anorexic patients was carried out by Crisp et al. (1970), who reported poor sleep quality (frequent awakenings during the night, early morning awakening) as well as a decreased amount of slow wave sleep. These observations were replicated by subsequent studies (Lacey et al., 1975; Neil et al., 1980; Levy et al., 1987). Regarding REM sleep, three groups (Neil et al., 1980; Katz et al., 1975; Walsh et al., 1985) reported shortened REM latencies in subgroups of anorexic patients. Most of these patients appeared to suffer from a concomitant affective disorder.

The sleep in bulimic patients was found to be largely indistinguishable from that of normal controls (Walsh et al., 1985; Hudson et al., 1987; Levy et al., 1987). However, Walsh et al. (1985) reported a tendency toward shortened REM latencies in their depressed bulimic patients. Weilburg et al. (1985) observed a "REM-like" latency (these REM periods were rather short and flat in the electro-oculogram) of about 53 min in two nondepressed bulimic patients. The only study comparing the sleep of bulimic patients with that of patients suffering from a primary affective disorder (Hudson et al., 1987) yielded a higher sleep continuity and a lower REM density in the bulimic patients.

In particular, the observed REM sleep alterations in patients with eating disorder, mainly in those manifesting a concomitant affective disorder, seem to be comparable to those well known in depression and therefore support the assumed biological association between a subgroup of eating disorders and depression.

Another possibility to test the assumption of a biological link between eating disorders and depression is provided by the cholinergic REM induction test (RIT). This test is based on the cholinergic-noradrenergic imbalance theory of depression (Janowsky et al., 1972) and the reciprocal interaction model of sleep regulation (Hobson et al., 1975; McCarley and Hobson, 1975). In short, the i.v. administration of cholinergic agents like physostigmine or arecoline during sleep leads to a hastened onset of the subsequent REM period in healthy subjects. In depressives, this effect is significantly more pronounced (for overview, see Sitaram et al., 1984). The only study in which the RIT was carried out in patients with anorexia nervosa was performed by Sitaram et al. (1984). They reported $66 \%$ of the anorexics with a coexisting affective disorder to be arecoline responders. In patients with a primary depression, an arecoline response was observed in $71 \%$. In contrast, in nondepressed anorexics and in healthy controls, the distributions of arecoline responders were low (12\% and $25 \%$, respectively). These observations, too, support a biological link between eating disorders and affective illness.

Recently, an alternative cholinergic agent, RS 86, was studied by Spiegel (1984). As compared to physostigmine and arecoline, this drug has some important advantages. It is an orally acting central muscarinic agonist with minor peripheral side effects and has a long half-life of about 8 hours. Spiegel (1984) demonstrated that $1.5 \mathrm{mg}$ RS 86 hastened the onset of the first REM period in healthy volunteers. These results were replicated by our group (Riemann et al., 1988) and were extended to depressed patients (Berger et al., 1985, in press), who showed a significantly more pronounced shortening of REM latency when compared to age-matched healthy controls.

The aims of the present study were twofold: (1) To elucidate further the sleep patterns of patients with eating disorders and (2) to test the assumption of an 
association between eating disorders and affective disorders by conducting the cholinergic RIT.

\section{Methods}

Subjects. Twenty patients ( 19 females, 1 male) with a diagnosis of anorexia nervosa (Feighner et al., 1972) were investigated. Mean age was 21.0 years and, on average, percentage of ideal body weight (IBW) was 70.3\% (Metropolitan Life Insurance Company, 1959). In addition, we examined 10 normal-weight bulimic women who met DSM-III criteria (American Psychiatric Association, 1980) for this syndrome. Mean age was 23.2 years and mean body weight was 98.0\% of IBW. All subjects were inpatients on an open psychiatric ward and had received no psychotropic medication during the last 3 months before the study.

All subjects were given the Composite International Diagnostic Interview (CIDI) (Semler et al., 1987) to assess the current and past diagnosis of major depression according to $D S M-I I I$ criteria. Nine anorexic and five bulimic patients qualified for a current and/or a lifetime diagnosis of major depression. In addition, the severity of depressive symptomatology was rated by the depression-relevant items of the Inpatient Multidimensional Psychiatric Scale (IMPS-D: subscales INP, RTD, IMF) (Lorr et al., 1962); a cutoff value of $15 \%$ of the theoretically possible maximum distinguishes well between depressed and nondepressed psychiatric patients (Berger et al., 1982).

The 10 healthy controls were carefully selected to match the age and gender distribution of the eating disorder samples. They were thoroughly screened for physical and psychiatric disorders and underwent an extensive semistructured psychiatric interview to ensure that they were free of a personal or family history of psychiatric disorders. In addition, their eating habits had to be undisturbed, and body weight had to be within the normal range ( $\pm 10 \% \mathrm{IBW}$ ).

Sleep. On average, 11 days after hospital admission, all patients slept for 3 consecutive nights in the laboratory. The same was true for the control subjects. Sleep was recorded between lights out $(2315 \mathrm{~h})$ and lights on $(0630 \mathrm{~h})$ using standard procedures (electroencephalogram, electrooculogram, and electromyogram). Records of night 3 were scored by two experienced raters according to standardized criteria (Rechtschaffen and Kales, 1968). REM latency was defined as the time interval from sleep onset (first occurrence of a sleep spindle/ $\mathrm{k}$ complex) until the first epoch of REM sleep; REM density was defined as the ratio of 3-sec mini-epochs per REM period including REMs to the total amount of all 3-sec mini-epochs per REM period $\times 100 \%$.

Cholinergic REM Induction Test (RIT). In addition to baseline electroencephalographic (EEG) sleep recordings, six anorexic ( 5 female, 1 male; mean age: $22.5 \pm S D 3.1$ years; mean body weight: $85.5 \pm$ SD $5.1 \%$ IBW; two of them displayed a current major depression) and six bulimic females (mean age: $21.5 \pm$ SD 2.7 years; mean body weight: $91.5 \pm$ SD $7.7 \%$ IBW; three with a current and one also with a lifetime diagnosis of major depression) participated in the RIT. On average, the severity of depressive symptomatology in these 12 patients was moderate (IMPSD: $23.9 \pm$ SD $8.8 \%$ maximum value). In bulimic patients, the RIT was performed immediately after the baseline period. For safety reasons, the RIT was performed in anorexic patients when they had reached a body weight of at least $80 \%$ IBW. Thirteen young healthy subjects $(8$ females, 5 males; mean age: $23.3 \pm$ SD 2.7 years) who were free of medical and psychiatric disorders and who had no history of affective disturbances served as a control group. For the purpose of the RIT, $1.5 \mathrm{mg}$ RS 86 and placebo were given at $2200 \mathrm{~h}$ in a random order. Sleep was recorded as mentioned above. The subjects, who were informed in detail about the possible side effects of the drug and consented to participate, were blind to the placebo-drug regime.

Statistics. Descriptive statistics include presentation of mean and standard deviations (SD). The Kruskal-Wallis $H$ test was conducted to test group effects. Group comparisons were computed either by the Mann-Whitney $U$ test (independent samples) or the Wilcoxon test (dependent samples). The level of significance was set at $5 \%$ (two-tailed). 


\section{Results}

The clinical characteristics of the subjects are presented in Table 1. Age and sex distributions were similar in all three groups. The percentage of IBW was significantly lower in the anorexic patients as compared to the bulimic patients and the control subjects $(p<0.001)$. In both anorexic and bulimic patients, body weight did not change between hospital admission and time of study (means: 0.2 and $0.0 \% \mathrm{IBW}$, respectively). The bulimic patients were more depressed than the anorexic patients ( $p$ $<0.001)$, and their illness lasted for a longer time $(p<0.01)$. The distribution of patients with a concomitant major depression was similar in both samples.

\section{Table 1. Clinical characteristics}

\begin{tabular}{lccc}
\hline & $\begin{array}{c}\text { Anorexia } \\
\text { nervosa } \\
(n=20)\end{array}$ & $\begin{array}{c}\text { Bulimia } \\
(n=10)\end{array}$ & $\begin{array}{c}\text { Controls } \\
(n=10)\end{array}$ \\
\hline Sex (F/M) & $19 / 1$ & $10 / 0$ & $9 / 1$ \\
Age & $21.0 \pm 3.1$ & $23.2 \pm 3.1$ & $23.1 \pm 3.1$ \\
$(20.0)$ & $(23.0)$ & $(23.0)$ \\
$\begin{array}{c}\text { Duration of illness } \\
\text { (months) }\end{array}$ & $\begin{array}{c}(29.0 \pm 33.4 \\
(30.0)\end{array}$ & $\begin{array}{c}77.4 \pm 25.7 \\
(81.0)\end{array}$ & - \\
$\begin{array}{c}\text { \% ldeal body weight } \\
\text { Restricters/ }\end{array}$ & $70.3 \pm 6.3$ & $98.0 \pm 15.5$ & $96.0 \pm 5.9$ \\
History of anorexia & $(71.5)$ & $(92.5)$ & $(95.0)$ \\
Major depression & $11(55 \%)$ & $6(60 \%)$ & 0 \\
Severity of depression & $9(45 \%)$ & $5(50 \%)$ & 0 \\
(IMPS-D; \% max. value $)$ & $19.5 \pm 8.4$ & $29.7 \pm 8.0$ & - \\
\hline
\end{tabular}

Note. $\mathrm{F}=$ female. $\mathrm{M}=$ male. IMPS-D = Inpatient Multidimensional Psychiatric Scale, depression-relevant subscales. Max = maximum. Major depression diagnosed according to DSM-III. Means, SDs, and medians in parentheses; are presented.

The results for the sleep parameters studied are presented in Table 2 . Sleep continuity did not differ among the three samples, except for a significantly lower sleep efficiency in the bulimic patients as compared to the controls $(p<0.05)$, indicated by increased intermittent wakefulness in the bulimic patients $(p<0.05)$. The sleep architecture of all three groups appeared quite similar. Likewise, REM sleep measures-in particular, REM latency-did not differ among the groups.

Spearman rank correlations were computed to investigate associations among clinical characteristics and sleep measures. The strongest links were observed in the bulimic patients: age showed a significant negative correlation with REM latency ( $r=$ $-0.65, p<0.05)$ and percentage of slow wave sleep (SWS) $(r=-0.87, p<0.01)$. Furthermore, age showed a significant positive correlation with early morning awakcning (EMA) $(r=0.67, p<0.05)$. In anorexic patients, all age-related coefficients werc nonsignificant. The same was observed in the controls, except for a strong positive correlation between age and intermittent time awake $(r=0.83, p<0.01)$. Percentage of IBW, duration of illness, and severity of depression (IMPS-D) were not correlated with any sleep measures, including those of REM sleep. 
Table 2. Sleep variables in anorexia, bulimia, and controls

\begin{tabular}{lccc}
\hline & $\begin{array}{c}\text { Anorexia } \\
(n=\mathbf{2 0})\end{array}$ & $\begin{array}{c}\text { Bulimia } \\
(n=\mathbf{1 0})\end{array}$ & $\begin{array}{c}\text { Controls } \\
(n=10)\end{array}$ \\
\hline Sleep period time $(\mathrm{min})$ & $408.8 \pm 27.5$ & $408.3 \pm 32.7$ & $413.7 \pm 17.0$ \\
Total sleep time $(\mathrm{min})$ & $392.5 \pm 37.5$ & $386.6 \pm 33.8$ & $405.4 \pm 19.1$ \\
Sleep efficiency $(\%)$ & $90.2 \pm 6.8$ & $87.9 \pm 6.7$ & $93.3 \pm 4.3$ \\
Sleep onset latency $(\mathrm{min})$ & $14.9 \pm 13.0$ & $22.1 \pm 17.6$ & $19.0 \pm 10.6$ \\
Intermittent awake $(\mathrm{min})$ & $15.9 \pm 18.4$ & $21.1 \pm 23.7$ & $7.8 \pm 11.0$ \\
Early morning awake $(\mathrm{min})$ & $10.8 \pm 16.8$ & $9.6 \pm 19.1$ & $2.4 \pm 4.8$ \\
Stage 2 (\% SPT) & $50.1 \pm 9.3$ & $46.2 \pm 12.9$ & $52.1 \pm 5.7$ \\
SWS (\% SPT) & $20.2 \pm 10.1$ & $18.5 \pm 9.1$ & $19.6 \pm 7.6$ \\
REM (\% SPT) & $19.2 \pm 6.5$ & $20.4 \pm 6.1$ & $19.4 \pm 3.7$ \\
REM latency (min) & $69.4 \pm 26.1$ & $94.0 \pm 79.1$ & $72.0 \pm 31.5$ \\
REMP 1 duration (min) & $14.7 \pm 14.9$ & $19.3 \pm 17.1$ & $14.6 \pm 8.6$ \\
REMP 1 density $\%$ ) & $19.7 \pm 7.4$ & $20.3 \pm 12.0$ & $22.4 \pm 8.5$ \\
Mean REM density $(\%)$ & $25.8 \pm 8.5$ & $28.0 \pm 9.8$ & $32.2 \pm 10.5$ \\
\hline
\end{tabular}

Note. SPT = sleep period time. SWS = slow wave sleep. REM = rapid eye movement. REMP = REM period. Values are mean $\pm S D$.

The clustering of the nine anorexic and five bulimic patients with a concomitant diagnosis of a major depression and those without resulted in a similar distribution of age, gender, and body weight of these two groups. The severity of depressive symptomatology tended to be increased in the depressed sample (IMPS-D: mean $\pm \mathrm{SD}=25.8$ $\pm 9.7 \%)$ as compared to the nondepressed patients $(20.3 \pm 8.8 \%, p<0.08)$. With regard to sleep measures, the depressed eating disorder patients exhibited a significantly later final awakening than their nondepressed counterparts $(3.4 \pm 8.3 \mathrm{~min}$ and $16.6=20.7$ min, respectively; $p<0.05)$, and their relative amount of SWS was increased $(23.0 \pm$ $10.1 \%$ and $16.7 \pm 8.4 \%$, respectively; $p<0.05$ ). Again, REM sleep variables did not differ among the groups. Fig. 1 shows that in all samples the distribution of REM latency was nearly identical. The only two subjects exhibiting a REM latency $<45$ min were a restricting anorexic and a bulimic patient without an anorexic history, both nondepressed.

Sleep was similar in both depressed and nondepressed anorexic patients. As compared to their nondepressed counterparts, the depressed bulimic patients had significantly less EMA (means: $0.2 \pm 0.3$ vs. $19.0 \pm 24.4 \mathrm{~min} ; p<0.05$ ). No further differences were observed.

REM Induction Test (RIT). The RIT was performed in 12 patients with an eating disorder ( 6 anorexics and 6 bulimics) and in 13 healthy controls. The age distribution was similar in the patient sample and in the controls $(21.9 \pm 2.8$ years and $23.3 \pm 2.7$ years, respectively).

The placebo sleep measures were similar in both groups, except that a significantly shorter sleep period time was observed in the patients with eating disorders $(p<0.05)$. After the administration of $1.5 \mathrm{mg}$ RS 86, REM latency was significantly shortened in both the patients suffering from eating disorders and the healthy controls (Table 3 ). On average, the degree of shortening was nonsignificantly more pronounced in the 
Table 3. Sleep patterns in eating disorders $(n=12)$ and healthy controls $(n=13)$ during placebo and RS 86 nights

\begin{tabular}{|c|c|c|c|c|c|c|}
\hline & \multicolumn{3}{|c|}{ Eating disorders } & \multicolumn{3}{|c|}{ Controls } \\
\hline & Placebo & RS 86 & $p<$ & Placebo & RS 86 & $p<$ \\
\hline Sleep period & $383.3 \pm 49.31$ & $398.2 \pm 23.6$ & & $419.3 \pm 17.6$ & $412.8 \pm 19.2$ & \\
\hline Sleep efficiency $(\%)$ & $87.5 \pm 10.9$ & $87.3 \pm 11.3$ & & $94.1 \pm 3.9$ & $92.4 \pm 3.1$ & 0.05 \\
\hline Intermittent awake & $10.7 \pm 17.7$ & $21.2 \pm 26.5$ & & $9.7 \pm 9.4$ & $13.0 \pm 10.1$ & \\
\hline Sleep onset latency & $14.9 \pm 12.4$ & $18.9 \pm 11.0$ & & $14.0 \pm 10.0$ & $17.0 \pm 7.4$ & \\
\hline SWS $\%$ SPT & $22.7 \pm 8.2$ & $10.9 \pm 9.8$ & 0.01 & $20.0 \pm 7.5$ & $14.4 \pm 7.4$ & 0.01 \\
\hline REM \% SPT & $20.3 \pm 4.2$ & $22.0 \pm 5.2$ & & $18.3 \pm 2.8$ & $21.0 \pm 3.6$ & 0.05 \\
\hline REM latency & $75.2 \pm 22.2$ & $53.3 \pm 22.5$ & 0.01 & $71.0 \pm 27.2$ & $61.3 \pm 30.7$ & 0.05 \\
\hline REMP 1 duration & $14.3 \pm 8.2$ & $19.9 \pm 13.8$ & & $11.5 \pm 9.4$ & $17.6 \pm 12.2$ & \\
\hline REMP 1 density $(\%)$ & $21.7 \pm 7.1$ & $26.4 \pm 12.0$ & & $26.0 \pm 12.8$ & $27.2 \pm 12.0$ & \\
\hline Mean REM density (\%) & $28.9 \pm 4.2$ & $29.0 \pm 10.2$ & & $34.3 \pm 11.8$ & $33.7 \pm 9.7$ & \\
\hline
\end{tabular}

Note. SWS = slow wave sleep. SPT = sleep period time. $\mathrm{REM}=$ rapid eye movement. REMP $=$ REM period. Values are mean $\pm S D$; units are min unless otherwise specified. The $p$ values were obtained using the Wilcoxon test.

1. $p<0.05$. comparison to healthy controls-placebo. $U$ test.

patients with an eating disorder (mean: $21.9 \pm 15.7 \mathrm{~min}$ ) than in the controls (mean: 9.8 $\pm 35.4 \mathrm{~min} ; p<0.30$ ). In the controls, the lower mean shortening of REM latency can be mainly attributed to the fact that after the application of RS 86 one subject probably skipped the first REM period and therefore exhibited a lengthening of REM latency of $93 \mathrm{~min}$ (Fig. 2). Furthermore, REM latencies of the depressed $(n=6)$ and the nondepressed $(n=6)$ patients with eating disorders were similar during the placebo night (means: $69.6 \pm 7.4$ vs. $81.0 \pm 30.6 ; p<0.65$ ) as well as during the drug night (means: $50.2 \pm 6.8$ vs. $56.3 \pm 32.3 ; p<0.75$ ). During the drug night, the only patient showing a REM latency $<25$ min was a nondepressed bulimic.

Regarding sleep architecture, in both the patients suffering from eating disorders and in healthy subjects, the percentages of SWS were significantly decreased during the drug nights. In addition, percentage of REM sleep was significantly increased in the controls (Table 3 ). In both samples, phasic REM sleep events were unaffected by RS 86.

\section{Discussion}

We found no major differences among the all-night sleep EEGs in anorexic and bulimic patients, and age-and gender-matched healthy controls. These results support recent findings of Walsh et al. (1985), Levy et al. (1987), and Hudson et al. (1987), who reported sleep patterns in their normal-weight bulimic patients which were similar to those in healthy controls and anorexic patients. The observed similarity of sleep in anorexic patients and healthy controls, however, seems to contradict some earlier reports in which the most robust findings were a disturbance of sleep continuity measures (Crisp et al., 1970; Lacey et al., 1975; Foster et al., 1976; Walsh et al., 1985) and a reduction of SWS or REM sleep (Crisp et al., 1970; Foster et al., 1976; Neil et al., 1980; Levy et al., 1987). Furthermore, REM latency was shortened in the overall sample of anorexic patients (Katz et al., 1984) or in certain subgroups (Neil et al., 1980; 
Fig. 1. Distribution of REM latency in anorexic, bulimic, and healthy subjects

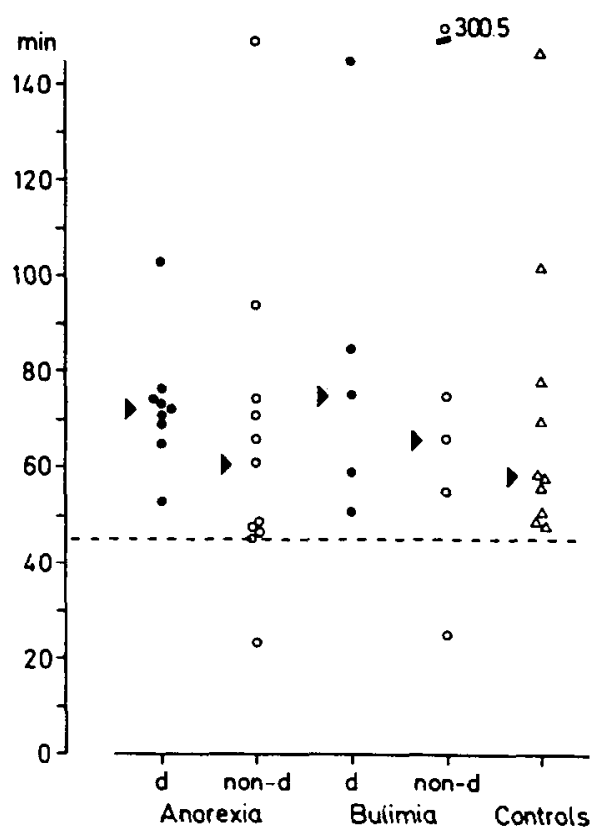

Anorexics, $n=20$; bulimics, $n=10$; healthy subjects, $n=10$. Dark circles = patients also meeting OSM $\cdot 1 / 1$ criteria for major depression. Open circles = nondepressed patients. Arrows $=$ median. REM $=$ rapid eye movement.
Fig. 2. Distribution of REM latency during the RIT in patients with eating disorders and healthy subjects

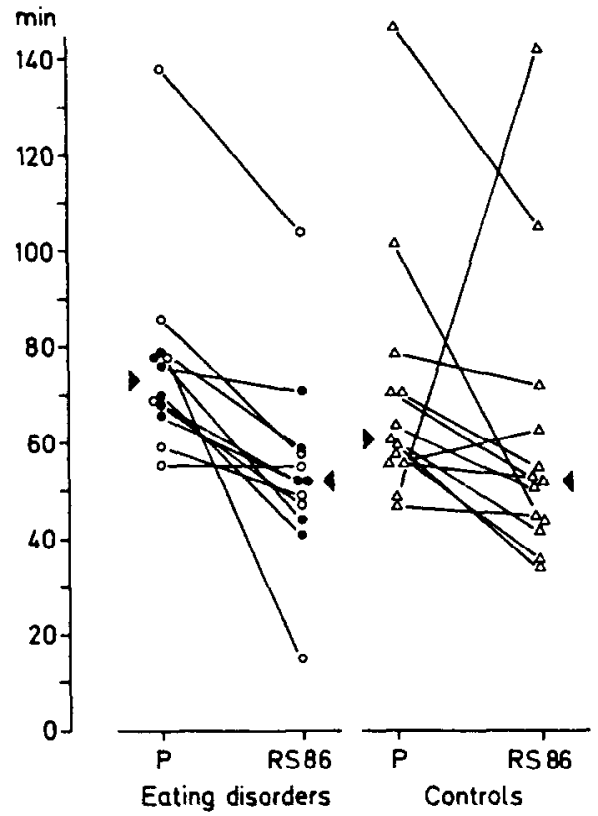

Anorectic patients, $n=6$; butimic patients, $n=6$; age-matched healthy subjects, $n=13$. REM = rapid eye movement. RIT = REM induction test. Dark circles = patients also meeting $D S M-/ / /$ criteria for major depression. Open circles $=$ nondepressed patients. Arrows - median.

Walsh et al., 1985). Some methodological differences between these studies and the present one may serve to explain discrepancies in results. Crisp et al. (1970) and Lacey et al. (1975) focused on sleep changes during weight restoration and reported the sleep to be disturbed at admission. These studies did not include healthy controls. On the other hand, Foster et al. (1976) did not observe a marked disturbance in sleep continuity at the time of admission but after a refeeding period in their anorexic patients as compared to controls. The possible influence of weight gain on sleep seems very unlikely in the present study, as there was no weight change in either the anorexic or the bulimic patients between hospital admission and the time of study. Walsh et al. (1985) reported sleep data for night 1 and for night 2 during which the subjects slept with an i.v. catheter. Both conditions are known to induce arousals in the sleep of healthy subjects (Coble et al., 1974; Browman and Cartwright, 1980; Adam, 1982; Jarrett et al., 1984). To minimize the possible contamination of the sleep data by adaptation effects, we analyzed the polysomnograms of only night 3 . The inconsistently reported reduction of SWS may be due to different characteristics of the samples investigated. Levy et al. (1987) reported a low amount of SWS, especially in the dietary restricting anorexic patients. Another possible influence on sleep architec- 
ture may be that of varying compositions of nourishment. Phillips et al. (1975) demonstrated in healthy subjects that diets containing different proportions of basic constituents (e.g., carbohydrate and fat) affected the amount of SWS or REM sleep to a different degree.

A further important factor influencing sleep is an affective illness. REM sleep abnormalities are a common feature in patients suffering from a primary depressive disorder (e.g., Gillin et al., 1984). Therefore, the observation of shortened REM latencies in patients with eating disorders, especially in depressed subsamples, is cited as a hint for the assumed biological link between eating and affective disorders (Neil et al., 1980; Katz et al., 1984; Walsh et al., 1985). However, Katz et al. (1984) and Walsh et al. (1985) diagnosed their patients according to $D S M-I I I$ criteria which do not exclude patients with a primary depression as is the case with the Feighner criteria. Neil et al. (1980) used the Feighner criteria but also included patients with secondary anorexia in which primary depression can be present. Therefore, it cannot be ruled out that in these studies the observed shortened REM latencies might be due to patients suffering from a primary depression. In the present study, we investigated the sleep characteristics of patients with eating disorders (according to Feighner criteria in anorexic patients) who additionally fulfilled $D S M-I I I$ criteria for major depression. The obtained observations were not in line with the assumption of "depression-like" sleep abnormalities in depressed anorexic and depressed bulimic patients, thus supporting the similar findings of Levy et al. (1987) and Hudson et al. (1987). In particular, this applies to REM sleep measures such as REM latency and both the duration and density of REM period 1. The only two patients exhibiting a REM latency $<45 \mathrm{~min}$ were both nondepressed. Furthermore, the severity of depression was not correlated with any sleep measures, and in particular was not correlated with REM sleep measures. However, it should be mentioned that age was negatively associated with REM latency in bulimic patients. This link is reported to be typical in depression and does not characterize healthy subjects (Ulrich et al., 1980; Gillin et al., 1981; Kupfer et al., 1982; Lahmeyer et al., 1983).

Moreover, the results of the cholinergic RIT do not support the assumed biological link between eating and affective disorders. Indeed, after administration of the cholinomimetic agent RS 86 in the patients with eating disorders, a hastened onset of REM period 1 and a reduction of SWS was observed, thus seeming to mimic depression-like sleep patterns. However, these effects of RS 86 on sleep did not differ between depressed and nondepressed patients with eating disorders and were quite similar to those observed in young healthy subjects. Recently, Berger et al. (1985, in press) demonstrated that the effect of $1.5 \mathrm{mg}$ RS 86 on REM latency in depressed patients was significantly more pronounced (means: $58.1 \mathrm{~min}$ vs. $15.1 \mathrm{~min}$ ) than in agematched healthy subjects ( $74.1 \mathrm{~min}$ vs $50.0 \mathrm{~min})$. On the placebo night, a REM latency $<45 \mathrm{~min}$ was found in only $25 \%$ of the depressives, whereas on the drug night $88 \%$ of the patients had a REM latency $<25 \mathrm{~min}$. These data support the assumption of a disturbance of the REM sleep regulating system during depression. If this does not become manifest during baseline sleep, as is true in young depressives (Taub et al., 1978; Hawkins et al., 1985; Cashman et al., 1986; Goetz et al., 1987; Hudson et al., 1987; Lauer et al., 1987), then it can be demasked by a cholinergic agent. In the present sample of patients with eating disorders, only one bulimic patient without a concomit- 
ant diagnosis of a major depression had a REM latency $<25$ min during the drug night. This observation is not in accord with the results reported by Sitaram et al. (1984), who found that $66 \%$ of anorexic patients with a coexisting affective disorder were arecoline responders (reduction of the second $R E M$ latency $>19 \mathrm{~min}$ ) as compared to only $12 \%$ of the nondepressed anorexic patients. However, there are some differences in methodology and patient sample between the study of Sitaram et al. and our own study. They infused $0.5 \mathrm{mg}$ arecoline $25 \mathrm{~min}$ after the end of REM period 1, and their depressed anorexics also had a personal and/or family history of affective illness. In the present study, only one depressed bulimic patient had a personal history of an affective disorder. However, her REM latencies were well within the range of the total sample. Furthermore, the significance of an affective trait for the response to the RIT is put into question by the results reported by Berger et al. (in press), who observed no differential effects of RS 86 on sleep in entirely remitted depressives and healthy controls. In both samples, this effect was significantly minor as compared to patients suffering from a current episode of primary depression. The fact that we performed the RIT in the anorexic patients when they had reached a minimum of at least $80 \%$ of IBW does not seem to have been a significant factor since Sitaram et al. (1984) demonstrated that low-and normal-weight anorexic patients did not differ in response to the RIT.

In conclusion, all-night sleep EEGs in anorexic and bulimic patients were largely indistinguishable from those in age-matched healthy controls. In addition, no depression-like sleep patterns were observed in the eating disorders, particularly in those suffering from a concomitant major depression. The results from the cholinergic RIT furthermore do not support the assumption of a biological link between eating disorder and depression.

\section{References}

Adam, K. Sleep is changed by blood sampling through an indwelling venous catheter. Sleep, 5 , 154 (1982).

American Psychiatric Association. DSM-III: Diagnostic and Statistical Manual of Mental Disorders. 2nd ed. APA, Washington, DC (1980).

Bcrger, M., Doerr, P., Lund, R., Bronisch, T., and von Zerssen, D. Neuroendocrinological and neurophysiological studies in major depressive disorders: Are there biological markers for the endogenous subtype? Biological Psychiatry, 17, 1217 (1982).

Berger, M., Höchli, D., Zulley, J., Lauer, C., and von Zerssen. D. Cholinomimetic drug RS 86, REM sleep, and depression. Lancet, I, 1385 (1985).

Berger, M., Riemann, D., Höchli, D., and Spiegel, R. The cholinergic REM sleep-inductiontest with RS 86: State or trait marker of depression? Archives of General Psychiatry (in press).

Browman, C.P., and Cartwright, R.D. The first night effect on sleep and dreams. Biological Psychiatry, 15, 809 (1980).

Bruch, H. Eating Disorders: Obesity, Anorexia Nervosa and the Person Within. Basic Books, New York (1973).

Cantwell, D.P., Sturzenberger, S., Burroughs, J., Salkin, B., and Green, J.K. Anorexia nervosa: An affective disorder? Archives of General Psychiatry, 34, 1087 (1977).

Cashman, M., Coble, P., McCann, B.S., Taska, I., Reynolds, C.F. III, and Kupfer, D. J. Sleep markers for major depressive disorder in adolescent patients. Sleep Research, 15, 91 (1986).

Coble, P., McPartland, R.J., Silva, W.J., and Kupfer, D.J. Is there a first night effect? Biological Psychiatry, 9, 215 (1974). 
Crisp, A.H., Stonehill, E., and Fenton, G.W. An aspect of the biological basis of the mind-body apparatus: The relationship between sleep, nutritional state and mood in disorders of weight. Psychotherapy and Psychosomatics, 18, 161 (1970).

Fairburn, C.G. Bulimia: Its epidemiology and management. Psychiatric Annals, 13, 953 (1983).

Feighner, J.P., Robins, E., Guze, S., Woodruff, R.A., Winokur, G., and Munoz, R. Diagnostic criteria for use in psychiatric research. Archives of General Psychiatry, 26, 57 (1972).

Foster, F.G., Kupfer, D.J., Spiker, D.G., Grau, T., Coble, P., and McPartland, R.J. EEG sleep in anorexia nervosa. Sleep Research, 5, 143 (1976).

Gillin, J.C., Duncan, W.C., Murphy, D.L., Post, R.M., Wehr, T.A., Goodwin, F.K., Wyatt, R.J., and Bunney, W.E., Jr. Age-related changes in sleep in depressed and normal subjects. Psychiatry Research, 4, 73 (1981).

Gillin, J.C., Sitaram, N., Wehr, T.A., Duncan, W., Post, R.M., Murphy, D.L., Mendelson, W.B., Wyatt, R.J., and Bunney, W.E., Jr. Sleep and affective illness. In: Post, R.M., and Ballenger J.C., eds. Neurobiology of Mood Disorders. Williams \& Wilkins Company, Baltimore, p. 157 (1984).

Goetz, R.R., Puig-Antich, J., Ryan, N., Rabinovich, H., Ambrosini, P.J., Nelson, B., and Ktawiec, V. Electroencephalographic sleep of adolescents with major depression and normal controls. Archives of General Psychiatry, 44, 61 (1987).

Halmi, K.A. Relationship of the eating disorders to depression: Biological similarities and differences. International Journal of Eating Disorders, 4, 667 (1985).

Hawkins, D.R., Taub, J.M., and Van de Castle, R.L. Extended sleep (hypersomnia) in young depressed patients. American Journal of Psychiatry, 142, 905 (1985).

Hobson, J.A., McCarley, R.W., and Wyzinski, P.W. Sleep cycle oscillation: Reciprocal discharge by two brain stem neuronal groups. Science, 189, 55 (1975).

Hudson, J.I., Pope, H.G., Jonas, J.M., Stakes, J.W., Grochocinski, V., Lipinski, J.F., and Kupfer, D.J. Sleep EEG in bulimia. Biological Psychiatry, 22, 820 (1987).

Hudson, J.I., Pope, H.G., Jonas, J.M., and Yurgelun-Todd, D. Phenomenologic relationship of eating disorders to major affective disorder. Psychiatry Research, 9, 345 (1983).

Janowsky, D.S., El-Jousef, M.K., and Davis, J.M. A cholinergic-adrenergic hypothesis of mania and depression. Lancet, II, 632 (1972).

Jarrett, D.B., Greenhous, J.B., Thompson, S. B., McEachran, A., Coble, P., and Kupfer, D.J. Effects of nocturnal intravenous cannulation upon sleep-EEG measures. Biological Psychiatry, 19, 1537 (1984).

Katz, J.L., Kuperberg, A., Pollack, C.P., Walsh, B.T., Zumoff, B., and Weiner, H. Is there a relationship between eating disorder and affective disorder? New evidence from sleep recordings. American Journal of Psychiatry, 141, 753 (1984).

Kupfer, D.J. The sleep EEG in diagnosis and treatment of depression. In: Rush, A.J., and Altshuler, K.Z., eds. Depression: Basic Mechanisms, Diagnosis, and Treatment. The Guilford Press, New York, p. 102 (1986).

Kupfer, D.J., Reynolds, C.F. III, Ulrich, R.F., Shaw, D.H., and Coble, P.A. EEG sleep, depression, and aging. Neurobiology of Aging, 3, 351 (1982).

Lacey, J.H., Crisp, A.H., Kalucy, R.S., Hartmann, M.K., and Chen, C.N. Weight gain and the sleeping electroencephalogram: Study of 10 patients with anorexia nervosa. British Medical Journal, 4, 556, (1975).

Lahmeyer, H.W., Poznanski, E.O., and Bellur, S.N. EEG sleep in depressed adolescents. American Journal of Psychiatry, 140, 1150 (1983).

Lauer, C., Riemann, D., and Berger, M. Age, REM sleep, and depression. Sleep Research, 16, 283 (1987). 
Levy, A.B., and Dixon, K.N. The relationship between anorexia nervosa and depression: A reevaluation. International Journal of Eating Disorders, 4, 389 (1985).

Levy, A.B., Dixon, K.N., and Schmidt, H.S. REM and delta sleep in anorexia nervosa and bulimia. Psychiatry Research, 20, 189 (1987).

Lorr, M., Klett, C.C., McNair, D.M., and Lasky, J.J. Inpatient Multidimensional Psychiatric Scale (IMPS). Consulting Psychologists Press, Palo Alto, CA (1962).

McCarley, R.W., and Hobson, J.A. Neuronal excitability modulation over the sleep cycle: A structural and mathematical model. Science, 189, 58 (1975).

Metropolitan Life Insurance Company. Statistical Bulletin of Metropolitan Life Insurance Company, 40, 1 (1979).

Neil, J.F., Merikangas, J.R., Foster, F.G., Merikangas, K.R., Spiker, D.G., and Kupfer, D.J. Waking and all-night sleep EEGs in anorexia nervosa. Clinical Electroencephalography, 11, 9 (1980).

Phillips, F., Chen, C.N., Crisp, A.H., Koval, J., McGuiness, B., Kalucy, R.S., Kalucy, E.C., and Lacey, J.H. Isocaloric dict changes and electroencephalographic slecp. Lancet, II, 723 (1975).

Rechtschaffen, A., and Kales, A., eds. A Manual of Standardized Terminology, Techniques, and Scoring System for Sleep Siages of Human Subjects. Department of Health, Education and Welfare, Washington, DC (1968).

Riemann, D., Joy, D., Höchli, D., Lauer, C., Zulley, J., and Berger, M. Influence of the Cholinergic Agonist RS 86 on Normal Sleep: Sex and Age Effects. Psychiatry Research. 24, 137 (1988).

Semler, G., Wittchen, H.U., Joschke, K., Zaudig, M., v. Geiso, T., Kaiser, S., v. Cranach, M., and Pfister, H. Test-retest reliability of a standardized psychiatric interview (DIS/CIDI). European Archives of Psychialry and Neurology in Science, 236, 214 (1987).

Sitaram, N., Gillin, J.C., and Bunney, W.E., Jr. Cholinergic and catecholaminergic receptor sensitivity in affective illness: Strategy and theory. In: Post, R.M., and Ballenger, J.C., eds. Neurobiology of Mood Disorders. Williams \& Wilkins Company, Baltimore, p. 629 (1984).

Spiegel, R. Effects of RS 86, an orally active cholinergic agonist, on sleep in man. Psychiatry Research, 11, I (1984).

Swift, W.J., Andrews, D., and Barklage, N.E. The relationship between affective disorder and eating disorders: A review of the literature. American Journal of Psichiatry, 143, 290 (1986).

Taub, J.M., Hawkins, D.R., and Van de Castle, R.L. Electrographic analysis of the sleep cycle in young depressed patients. Biological Psychiatry, 7, 203 (1978).

Ulrich, R.F., Shaw, D.H., and Kupfer, D.J. Effects of aging on EEG sleep in depression. Sleep, 3, 31 (1980).

Walsh, B.T., Goetz, R., Roose, S.P., Fingeroth, S., and Glassman, A.H. EEG-monitored sleep in anorexia nervosa and bulimia. Biological Psychiatry. 20, 947 (1985).

Weilburg, J.B., Stakes, J.W., Brotman, A., and Herzog, D. Sleep architecture in bulimia: A pilot study. Biologiral Psychiatry, 20, 199 (1985). 